\title{
KMUP-1 attenuates high glucose and transforming growth factor- $\beta 1$-induced pro-fibrotic proteins in mesangial cells
}

\author{
SHENG-HSUAN LIN ${ }^{1}$, ING-JUN CHEN ${ }^{2}$, CHAO-TANG CHUANG ${ }^{1}$, \\ WAN-TING HO ${ }^{3}$, LEA-YEA CHUANG ${ }^{3}$ and JINN-YUH GUH ${ }^{4,5}$
}

\author{
${ }^{1}$ Graduate Institute of Medicine, College of Medicine; Departments of ${ }^{2}$ Pharmacology and ${ }^{3}$ Biochemistry, \\ College of Medicine, Kaohsiung Medical University; ${ }^{4}$ Department of Internal Medicine, School of Medicine, \\ College of Medicine, Kaohsiung Medical University; ${ }^{5}$ Department of Internal Medicine, \\ Kaohsiung Medical University Hospital, Kaohsiung 80708, Taiwan, R.O.C.
}

Received December 14, 2015; Accepted January 26, 2017

DOI: $10.3892 / \mathrm{mmr} .2017 .6486$

\begin{abstract}
We have previously demonstrated that KMUP-1, a xanthine-based nitric oxide enhancer, attenuates diabetic glomerulosclerosis, while increasing renal endothelial nitric oxide synthase expression in rats. However, the anti-fibrotic mechanisms of KMUP-1 treatment in diabetic nephropathy in terms of cell biology and transforming growth factor- $\beta 1$ (TGF- $\beta 1$ ) remain unclear. Therefore, the present study involved investigating the effects of KMUP-1 on high glucose (HG) or TGF- $\beta 1$-induced pro-fibrotic proteins in mouse mesangial (MES13) cells, and the effects of KMUP-1 on streptozotocin (STZ)-induced diabetic rats. It was identified that KMUP-1 $(10 \mu \mathrm{M})$ attenuated HG $(30 \mathrm{mM})$-induced cell hypertrophy while attenuating TGF- $\beta 1$ gene transcription and bioactivity in MES13 cells. In addition, KMUP- 1 attenuated TGF- $\beta 1$ ( $5 \mathrm{ng} / \mathrm{ml}$ )-induced $\mathrm{Smad} 2 / 3$ phosphorylation while attenuating HG or TGF- $\beta 1$-induced collagen IV and fibronectin protein expression. Furthermore, KMUP-1 attenuated HG-decreased Suv39h1 and H3K9me3 levels. Finally, KMUP-1 attenuated diabetes-induced collagen IV and fibronectin protein expression in STZ-diabetic rats at 8 weeks. In conclusion, KMUP-1 attenuates HG and TGF- $\beta 1$-induced pro-fibrotic proteins in mesangial cells and attenuation of TGF- $\beta 1$-induced signaling and attenuation of HG-decreased Suv39h1 expression may be two of the anti-fibrotic mechanisms of KMUP-1.
\end{abstract}

Correspondence to: Dr Jinn-Yuh Guh, Department of Internal Medicine, School of Medicine, College of Medicine, Kaohsiung Medical University, 100 Zihyou First Road, Kaohsiung 80708, Taiwan, R.O.C.

E-mail: guhjy@kmu.edu.tw

Dr Lea-Yea Chuang, Department of Biochemistry, College of Medicine, Kaohsiung Medical University, 100 Zihyou First Road, Kaohsiung 80708, Taiwan, R.O.C.

E-mail: chuangly@gmail.com

Key words: diabetic nephropathy, KMUP-1, transforming growth factor- $\beta 1$, kidney fibrosis

\section{Introduction}

The worldwide prevalence of diabetes mellitus is expected to reach 642 million people by 2,040 (1). Diabetic nephropathy (DN), which develops in $40 \%$ of diabetic patients, is the leading cause of end-stage renal disease in the majority of developed countries (1). DN is characterized by renal hypertrophy, glomerulosclerosis and renal fibrosis, which involves extracellular matrix (e.g. collagen and fibronectin) accumulation $(2,3)$. Hyperglycemia, transforming growth factor- $\beta 1$ (TGF- $\beta 1$ ) and deficient endothelial nitric oxide synthase (eNOS) are among the key pathogenic mechanisms of diabetic renal fibrosis (4). However, current supplementary pharmacological treatments, other than glycemic control and renin-angiotensin system blockade, have had limited success (1). Thus, the development of novel pharmacologic agents is required.

A previous study of the authors indicated that nitric oxide (NO)-cyclic guanosine monophosphate protein kinase (cGMP) inducers attenuate advanced glycation end-product-induced effects in renal fibroblasts (5). KMUP-1 is a synthetic xanthine-based derivative which enhances soluble guanylate cyclase (sGC), eNOS and cGMP (6). A previous study indicated that KMUP-1 attenuates rat diabetic glomerulosclerosis while increasing eNOS levels (7). However, the anti-fibrotic mechanisms of KMUP-1 in DN regarding cell biology and TGF- $\beta 1$ remain unclear.

As a result, the present study focused on elucidating the effects of KMUP-1 on high glucose (HG) or TGF- $\beta 1$-induced pro-fibrotic proteins in mouse mesangial (MES13) cells, as well as the effects of KMUP-1 on streptozotocin (STZ)-induced diabetic rats.

\section{Materials and methods}

Reagents. Cell culture media, Dulbecco's modified Eagle medium (DMEM) and F12, were obtained from Invitrogen; Thermo Fisher Scientific, Inc. (Waltham, MA, USA). Recombinant human TGF- $\beta 1$ was obtained from PeproTech, Inc. (Rocky Hill, NJ, USA). KMUP-1 was synthesized in the laboratory of the authors, the stock solution $(10 \mathrm{mM})$ was prepared by dissolving KMUP-1 in the solvent (10\% absolute 
alcohol, $10 \%$ propylene glycol and $2 \% 1 \mathrm{~N} \mathrm{HCl}$ ), according to previous studies (8-10).

Cells. Mouse kidney mesangial cells (MES13) were purchased from the American Type Culture Collection (cat. no.CRL-1927; Manassas, VA, USA). Cells were grown in DMEM/F12 (3:1) medium (with $6.67 \mathrm{mM}$ glucose) supplemented with $5 \%$ fetal bovine serum (FBS) and $1 \%$ penicillin/streptomycin in a humidified $5 \% \mathrm{CO}_{2}$ incubator at $37^{\circ} \mathrm{C}$. Cells were starved in serum-free $(0.5 \% \mathrm{FBS})$ media for $24 \mathrm{~h}$ prior to experiments in 5\% FBS medium. All cell culture materials were obtained from Gibco (Thermo Fisher Scientific, Inc.).

Cell viability. MES13 cells were cultured in 24-well plates $\left(5 \times 10^{3} /\right.$ well). After $24 \mathrm{~h}$, cells were treated with the control (KMUP-1 solvent at a final concentration of 1\%) or KMUP-1 for $72 \mathrm{~h}$. MTT $(0.5 \mathrm{mg} / \mathrm{ml}$; Sigma-Aldrich; Merck KGaA, Darmstadt, Germany) was incubated at $37^{\circ} \mathrm{C}$ for $4 \mathrm{~h}$ prior to harvesting. Following removal of the culture medium, cells were dissolved in dimethylsulfoxide (DMSO) and shaken for $10 \mathrm{~min}$. Formazan was dissolved by DMSO and the assay was quantified by determining the absorbance at $540 \mathrm{~nm}$ using an ELISA reader (Dynex Technologies GmbH, Denkendorf, Germany).

TGF- $\beta 1$ promoter activity and bioactivity. Human TGF- $\beta 1$ promoter activity was detected using the phTG5 plasmid, which was donated by Dr Jean-Louis Virelizier (Unité d'Immunologie Virale, Institut Pasteur, Paris, France) (11). The TGF- $\beta 1$ bioactivity reporter p3TP-lux, which contains the plasminogen activator inhibitor-1 promoter, was donated by Dr. Joan Massagué (Memorial Sloan Kettering Cancer Center, New York, USA) (12). Cells were cultured in 6-well plates at a density of $1.5 \times 10^{4}$ cells/well and transfected with $1 \mu \mathrm{g}$ of the phTG5 or p3TP-lux plasmid using Lipofectamine 2000 (Invitrogen; Thermo Fisher Scientific, Inc., Waltham, MA, USA) according to the manufacturer's instructions. Following $6 \mathrm{~h}$ of transfection, cells were treated with HG $(30 \mathrm{mM})$ or combined with KMUP-1 $(10 \mu \mathrm{M})$ for $72 \mathrm{~h}$. Luciferase activity was measured using the Dynatech ML1,000 luminometer (Dynatech Laboratories, Inc., Chantilly, VA, USA).

Immunoblotting. Briefly (13), MES13 cells were lysed using radioimmunoprecipitation assay (RIPA) buffer $(50 \mathrm{mM}$ Tris-HCl, pH 8.0, $150 \mathrm{mM} \mathrm{NaCl}, 1 \% \mathrm{NP}-40,1 \mathrm{mM} \mathrm{Na}_{3} \mathrm{VO}_{4}$, $50 \mathrm{mM} \mathrm{NaF}$ and $10 \mathrm{mM} \beta$-glycerol phosphate) containing $0.1 \%$ protease inhibitor cocktail (Merck KGaA). Cell proteins were extracted and quantified with a $\mathrm{DC}^{\mathrm{TM}}$ protein assay kit (Bio-Rad Laboratories, Inc., Hercules, CA). Proteins $(50 \mu \mathrm{g} /$ well) were separated by $10 \%$ SDS-PAGE and transferred to PolyScreen polyvinylidene difluoride membranes (PerkinElmer, Inc., Waltham, MA, USA). Following blocking for $2 \mathrm{~h}$ at room temperature with 5\% non-fat milk and rinsing with PBS, the membranes were probed with the primary antibodies overnight at $4^{\circ} \mathrm{C}$ and washed with $0.1 \%$ PBS-Tween-20 (PBST) 3 times (5 min each). The primary antibodies used were phosphorylated-Smad2/3 (p-Smad2/3; 1:1,000; cat. no. 8828), Smad2/3 (1:2,000; cat. no. 3102), Suv39h1 (1:1,500; cat. no. 8729) and H3K9me3 (1:2,000; cat. no. 9754), antibodies were obtained from Cell Signaling Technology, Inc.,
Danvers, MA, USA). Fibronectin (1:10,000; cat. no. AJ1297b) and collagen IV (1:2,000; cat. no. AP7369a) antibodies were obtained from Abgent, Inc. (San Diego, CA, USA), GAPDH $(1: 5,000$; cat. no. sc-25778) and $\alpha$-tubulin (1:5,000; cat. no. MS-581-P) were obtained from Santa Cruz Biotechnology, Inc. (Dallas, TX, USA) and Labvision/NeoMarkers (Thermo Fisher Scientific, Inc.), respectively. The membranes were then incubated in horseradish peroxidase (HRP)-conjugated anti-rabbit (1:5,000; cat. no. AP132P) or anti-mouse (1:5,000; cat. no. AP124P) secondary antibodies (Merck KGaA) for $1 \mathrm{~h}$ at room temperature and washed with $0.1 \%$ PBST 5 times ( 5 min each). The protein bands were detected by using the enhanced chemiluminescence ECL system (PerkinElmer, Inc.) and the bands were quantified by densitometric analysis (Image Studio Lite 5.25; LI-COR Biosciences, Lincoln, NE, USA).

Cell hypertrophy. Cell hypertrophy was determined by the ratio of whole cell protein lysates to total cell numbers (14). Briefly, MES13 cells were cultured in 6-well plates to $50 \%$ confluence and then treated with $\mathrm{HG}(30 \mathrm{mM})$ or $\mathrm{HG}+$ KMUP-1 $(10 \mu \mathrm{M})$ for 3 days. Following trypsinization, cells were washed twice with PBS and cell numbers were counted using a hemocytometer. Equal numbers of cells were lysed in RIPA buffer containing the protease inhibitor cocktail. Total protein content was measured by using the $\mathrm{DC}^{\mathrm{TM}}$ protein assay kit (Bio-Rad Laboratories, Inc.).

Animal experiments. Male Sprague-Dawley rats $(\mathrm{n}=23)$ weighing 200-250 g (aged 7 weeks) were purchased from BioLASCO Taiwan Co., Ltd. (Taipei, Taiwan) and were housed ( 3 per cage) in a temperature- $\left(22 \pm 2^{\circ} \mathrm{C}\right)$ and humidity $(50 \pm 10 \%)$-controlled room with a $12 \mathrm{~h} \mathrm{light/dark} \mathrm{cycle} \mathrm{in} \mathrm{the}$ Animal Center of Kaohsiung Medical University (Kaohsiung, Taiwan). Rats were divided into three groups: Control, streptozotocin (STZ)-diabetic and diabetic + KMUP-1. Briefly (15), after overnight fasting, rats received a single intraperitoneal injection of $55 \mathrm{mg} / \mathrm{kg} \mathrm{STZ} \mathrm{(Sigma-Aldrich;} \mathrm{Merck} \mathrm{KGaA)} \mathrm{in}$ $0.1 \mathrm{M}$ citrate buffer (diabetic, $\mathrm{n}=9$; diabetic + KMUP-1, $\mathrm{n}=9$ ) or citrate buffer (control, $n=5$ ). Thereafter, rats were given free access to food and water. Diabetic rats received Lantus insulin (Sanofi S.A., Paris, France) to maintain non-fasting blood glucose levels between 19.4 and $27.8 \mathrm{mmol} / \mathrm{l}$. The diabetic + KMUP-1 treatment group was intraperitoneally injected with KMUP-1 (dissolved in distilled water, $5 \mathrm{mg} / \mathrm{kg} / \mathrm{day}$ ) daily (16). Rats were perfused with normal saline and anesthetized intraperitoneally with sodium pentobarbital $(50 \mathrm{mg} / \mathrm{kg}$; Abbott Pharmaceutical Co., Ltd., Lake Bluff, IL, USA) at week 8. Kidneys were removed and kidney slices were immersed in $4 \%$ paraformaldehyde at room temperature for $24 \mathrm{~h}$. Kidney slices were embedded in the paraffin block and cut into sections (thickness, $4 \mu \mathrm{m}$ ) for immunohistochemical studies. All animal procedures were conducted in accordance with the national guidelines (17) and were approved by the Kaohsiung Medical University Animal Experiment Committee.

Immunohistochemistry. Briefly (15), tissue sections were rehydrated and deparaffinized in xylene and ethanol. The sections then underwent antigen retrieval in $10 \mathrm{mM}$ sodium citrate buffer by microwaving for $30 \mathrm{~min}$. Following this, 


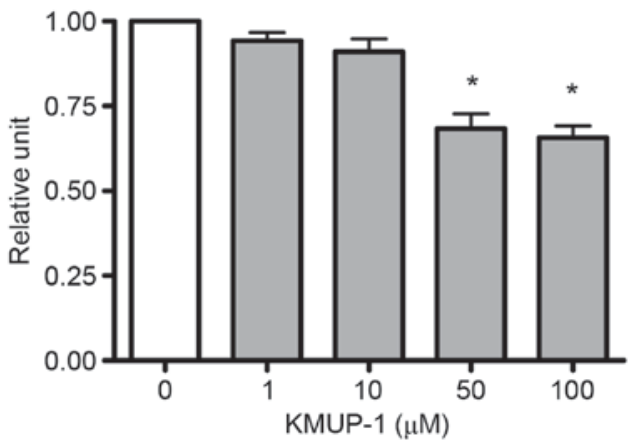

Figure 1. Dose-dependent effects of KMUP-1 on cell viability in MES-13 cells. Cells were treated with KMUP-1 in various doses (1-100 $\mu \mathrm{M}$, gray bars) for $72 \mathrm{~h}$. Cell viability was measured by MTT assay. The results were expressed as the mean \pm standard error of four independent experiments. ${ }^{*} \mathrm{P}<0.05$ vs. $0 \mu \mathrm{M}$ (blank bar).
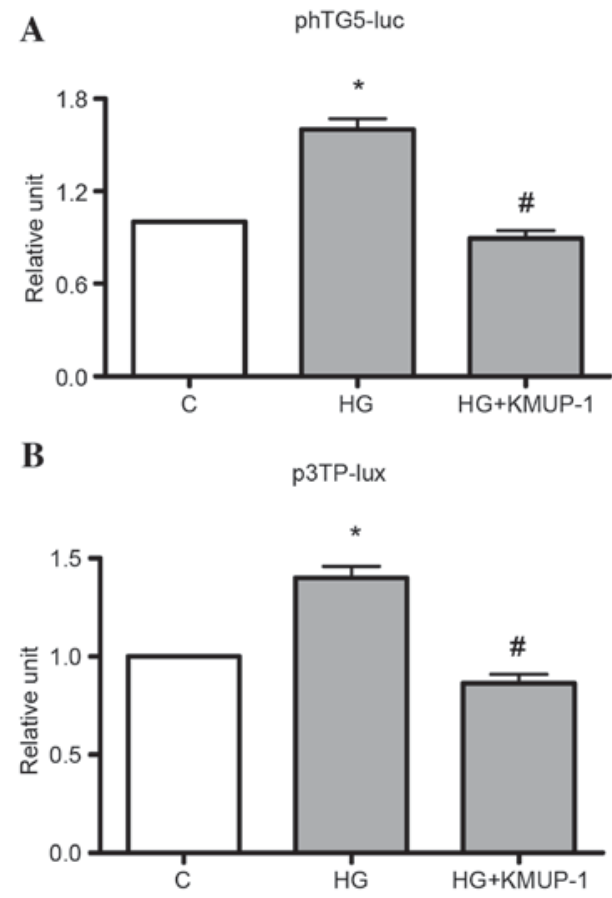

Figure 2. Effects of KMUP-1 on HG-induced TGF- $\beta 1$ transcriptional activity or bioactivity. Cells were transiently transfected with the phTG5-luc (TGF- $\beta 1$ transcriptional activity reporter) or 3TP-lux (TGF- $\beta 1$ bioactivity reporter) plasmids, cells were treated with $\mathrm{HG}(30 \mathrm{mM}$, gray bars) alone or in combination with KMUP-1 (10 $\mu \mathrm{M})$ for $72 \mathrm{~h}$. (A) Effects of KMUP-1 on TGF- $\beta 1$ transcriptional activity. (B) Effects of KMUP-1 on TGF- $\beta 1$ bioactivity. The results are expressed as the mean \pm standard error, in three independent experiments. " $\mathrm{P}<0.05$ vs. control. ${ }^{~} \mathrm{P}<0.05$ vs. $\mathrm{HG}$ alone. HG, high glucose; KMUP-1; TGF- $\beta 1$, transforming growth factor- $\beta 1$; $C$, control group.

preincubation of tissue sections with the blocking buffer was conducted for $30 \mathrm{~min}$ prior to incubation with primary antibodies overnight at $4^{\circ} \mathrm{C}$. Primary antibodies used were fibronectin (1:400, cat. no. AJ1297b) obtained from Abgent, Inc. and collagen IV antibodies (1:500, cat. no. ab6586) obtained from Abcam (Cambridge, UK). Following washing with PBST, sections were stained and incubated with DAB+ and the ready-to-use (undiluted) HRP-conjugated anti-rabbit secondary antibodies contained in the Dako REAL ${ }^{\mathrm{TM}}$ EnVision $^{\mathrm{TM}}$ Detection system (cat. no. K5007; Dako; Agilent Technologies, Inc., Santa Clara, CA, USA) for $30 \mathrm{~min}$ at room

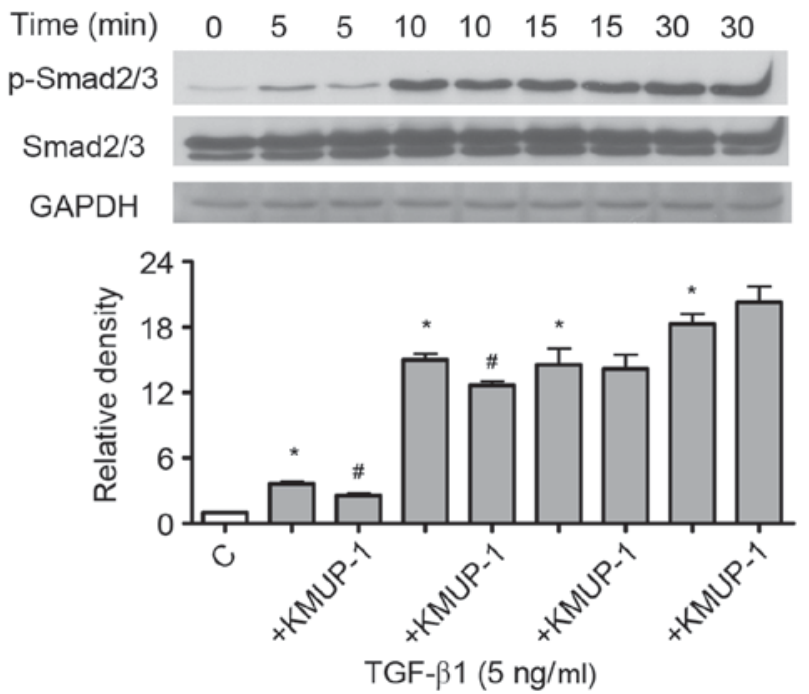

Figure 3. Effects of KMUP-1 on TGF- $\beta 1$-induced Smad2/3 signaling. Cells were treated with TGF- $\beta 1$ ( $5 \mathrm{ng} / \mathrm{ml}$, gray bars) alone or in combination with KMUP-1 (10 $\mu \mathrm{M}$, pre-treated for $30 \mathrm{~min}$ ) for 5-30 $\mathrm{min}$. Smad2/3, p-Smad2/3 and GAPDH were measured by immunoblotting. The results were expressed as the ratio of $\mathrm{p}-\mathrm{Smad} 2 / 3$ and $\mathrm{Smad} 2 / 3$ and expressed as the mean \pm standard error of three independent experiments. ${ }^{*} \mathrm{P}<0.05$ vs. control, ${ }^{\#} \mathrm{P}<0.05$ vs TGF- $\beta 1$ alone. TGF- $\beta 1$, transforming growth factor- $\beta 1 ; \mathrm{p}-$, phosphorylated; GAPDH, glyceraldehyde 3-phosphate dehydrogenase; C, control group.

temperature, according to the manufacturer's instructions, and counterstained with hematoxylin.

Statistical analysis. Statistical analyses were performed by using Stata 13.1 software (StataCorp LP, College Station, TX, USA). Data were expressed as the mean \pm standard error. Unpaired Student's $t$-tests were used for the comparison between two groups. $\mathrm{P}<0.05$ was considered to be statistically significant.

\section{Results}

KMUP-1 attenuated HG-induced TGF- $\beta 1$ bioactivity and gene transcriptional activity in MES13 cells. The present study investigated the effects of KMUP-1 on cell viability of MES13 cells to determine the optimum concentration of KMUP-1. MES13 cells were treated with KMUP-1 (1-100 $\mu \mathrm{M})$ for $72 \mathrm{~h}$ and cell viabilities were measured using an MTT assay. The optimum concentration of KMUP-1 was determined to be $10 \mu \mathrm{M}$ (Fig. 1).

TGF- $\beta 1$ gene transcriptional activity or TGF- $\beta 1$ bioactivity was measured by transient transfection of phTG5 or p3TP-lux, respectively. It was identified that KMUP-1 $(10 \mu \mathrm{M})$ attenuated HG (30 mM)-induced TGF- $\beta 1$ gene transcriptional activity or TGF- $\beta 1$ bioactivity at $72 \mathrm{~h}$ (Fig. 2).

KMUP-1 attenuated TGF- $\beta 1$-induced smad2/3 phosphorylation. Since TGF- $\beta 1$ gene transcriptional activity and TGF- $\beta 1$ bioactivity were attenuated by KMUP-1, the present study examined whether KMUP-1 also attenuated TGF- $\beta 1-S m a d$ signaling pathway. TGF- $\beta 1(5 \mathrm{ng} / \mathrm{ml})$ increased phosphorylation of Smad2/3 in a time-dependent manner (5-30 min; Fig. 3). Furthermore, KMUP-1 $(10 \mu \mathrm{M})$ attenuated TGF- $\beta 1$-induced p-Smad2/3 expression at 5-10 $\mathrm{min}(5 \mathrm{ng} / \mathrm{ml}$; Fig. 3$)$. 
A
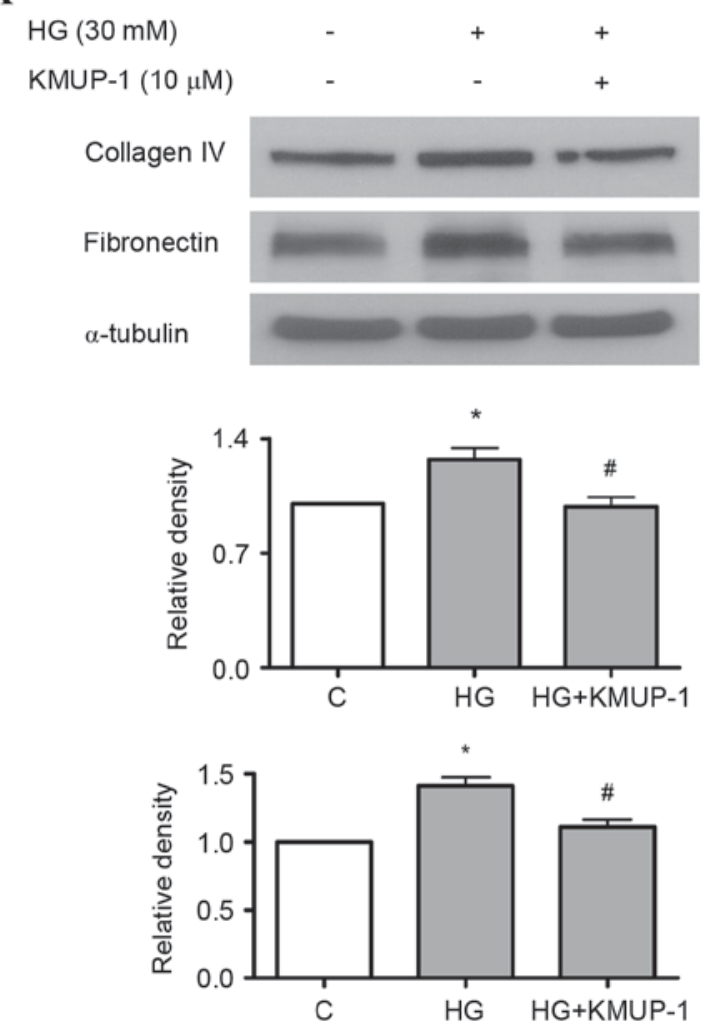

B

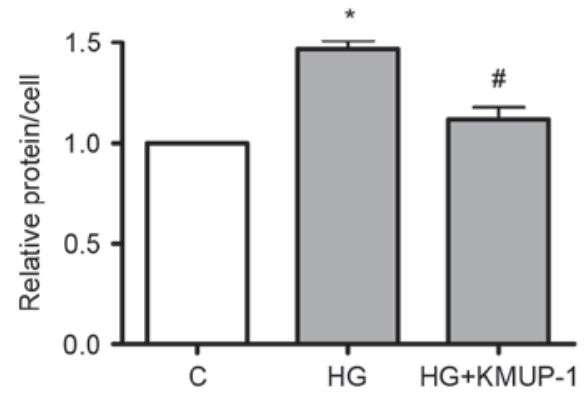

Figure 4. Effects of KMUP-1 on HG-induced collagen IV or fibronectin expression and cell hypertrophy. Cells were treated with HG (30 mM, gray bars) alone or in combination with KMUP-1 $(10 \mu \mathrm{M}$, pre-treated for $30 \mathrm{~min})$ for $72 \mathrm{~h}$. Collagen IV, fibronectin and $\alpha$-tubulin levels were measured by immunoblotting. The results were expressed as the ratio of collagen IV and $\alpha$-tubulin or as the ratio of fibronectin and $\alpha$-tubulin. Cell hypertrophy was measured by the ratio of total protein to cell number. (A) Effects of HG on collagen IV or fibronectin protein expression. (B) Effects of HG on cell hypertrophy. The results were expressed as the mean \pm standard error of three independent experiments. ${ }^{*} \mathrm{P}<0.05$ vs. control, ${ }^{\sharp} \mathrm{P}<0.05$ vs. HG group. HG, high glucose; $\mathrm{C}$, control group.

A

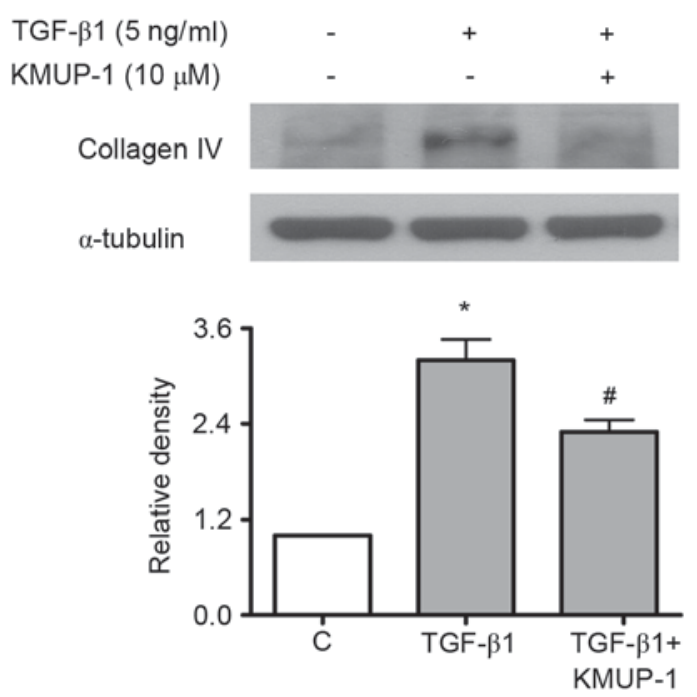

B

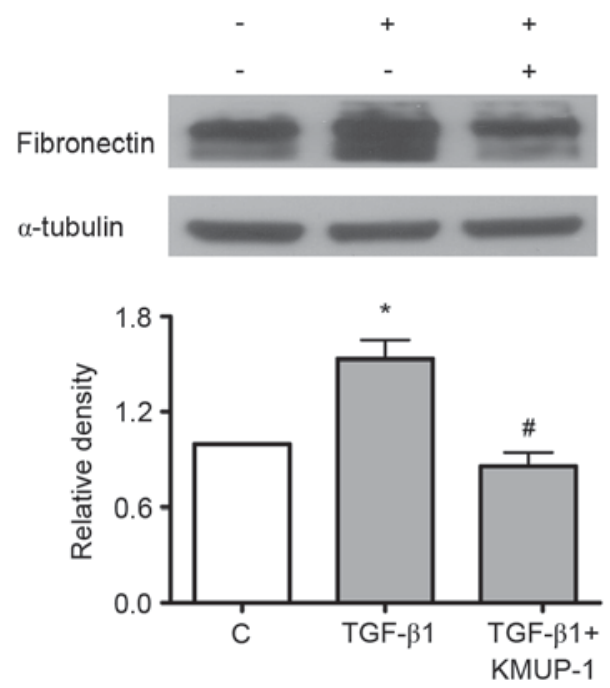

Figure 5. Effects of KMUP-1 on TGF- $\beta 1$-induced collagen IV or fibronectin expression. Cells were treated with TGF- $\beta 1$ ( $5 \mathrm{ng} / \mathrm{ml}$, gray bars) alone or in combination with KMUP-1 (10 $\mu \mathrm{M}$, pre-treated for $30 \mathrm{~min}$ ) for $72 \mathrm{~h}$. Collagen IV, fibronectin and $\alpha$-tubulin levels were measured by immunoblotting. (A) Effects of KMUP-1 on TGF- $\beta 1$-induced collagen IV protein expression. (B) Effects of KMUP-1 on TGF- $\beta 1$-induced fibronectin protein expression. The results were expressed as the ratio of collagen IV and $\alpha$-tubulin or as the ratio of fibronectin and $\alpha$-tubulin and expressed as the mean \pm standard error of the mean of three independent experiments. ${ }^{*} \mathrm{P}<0.05$ vs. control, ${ }^{\#} \mathrm{P}<0.05$ vs. TGF- $\beta 1$ group. TGF- $\beta 1$, transforming growth factor- $\beta 1$; $\mathrm{C}$, control group.

KMUP-1 attenuated HG or TGF- $\beta 1$-induced collagen IV or fibronectin protein expression. Both HG and TGF- $\beta 1$ have been previously reported to increase fibronectin and collagen
IV protein expression in mesangial cells $(18,19)$. As a result, the present study investigated the effects of KMUP-1 on HG or TGF- $\beta 1$-induced fibronectin and collagen IV protein 
A

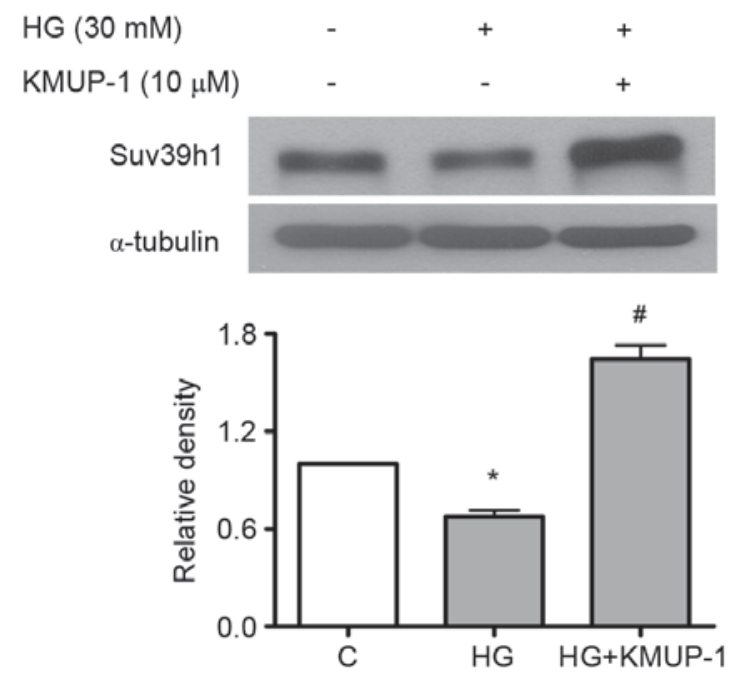

B
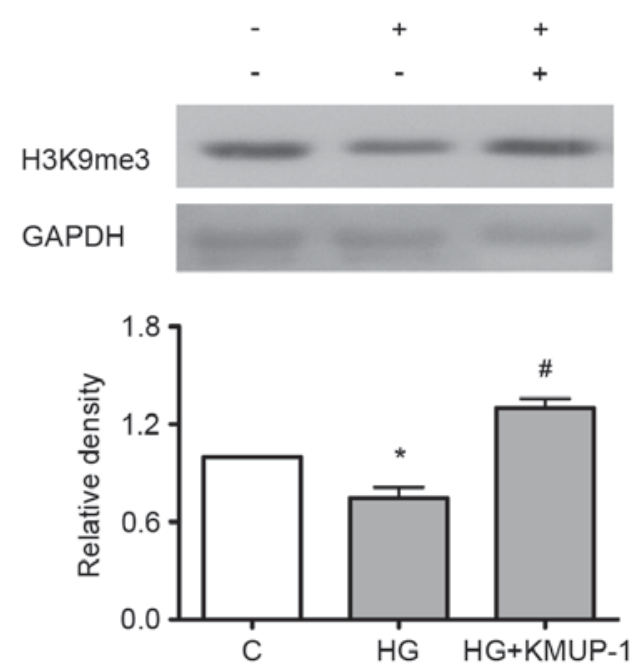

Figure 6. Effects of KMUP-1 on HG-decreased Suv39h1 and H3K9me3 protein expression. Cells were treated with high glucose (30 mM, gray bars) alone or in combination with KMUP-1 (10 $\mu \mathrm{M})$ for $72 \mathrm{~h}$. Suv39h1, H3K9me3, $\alpha$-tubulin and GAPDH levels were measured by immunoblotting. Suv39h1 was normalized to $\alpha$-tubulin whereas H3K9me3 was normalized to GAPDH. (A) Effects of KMUP-1 on HG-decreased Suv39h1 protein expression. (B) Effects of KMUP-1 on HG-decreased H3K9me3 protein expression. The results were expressed as the mean \pm standard error of three independent experiments. "P<0.01 vs. control, ${ }^{\text {\#}} \mathrm{P}<0.05$ vs. HG group. HG, high glucose; GAPDH, glyceraldehyde 3-phosphate dehydrogenase; $\mathrm{C}$, control group.

expression. KMUP-1 (10 $\mu \mathrm{M})$ was demonstrated to attenuate HG (Fig. 4A) or TGF- $\beta 1$ (5 ng/ml)-induced fibronectin and collagen IV protein expression at $72 \mathrm{~h}$ (Fig. 5).

KMUP-1 attenuated HG-induced cell hypertrophy. A previous study identified that KMUP-1 decreased cardiac hypertrophy via the NO/cGMP pathway (20). In addition to extracellular matrix accumulation, DN is characterized by renal (including mesangial cell) hypertrophy (21). In addition, DN is associated with NO deficiency (22). For example, eNOS knockout mice develop diabetic renal hypertrophy while soluble guanylate cyclase enhancers attenuate DN $(23,24)$. Therefore, the authors studied the effects of KMUP-1 on HG-induced cell hypertrophy. KMUP-1 (10 $\mu \mathrm{M})$ attenuated HG-induced cell hypertrophy at $72 \mathrm{~h}$ (Fig. 4B).

KMUP-1 attenuated HG-reduced histone methyltransferase Suv39h1. Suv39h1 is a histone lysine methyltransferase, which induces the gene-silencing $\mathrm{H} 3 \mathrm{~K} 9 \mathrm{me} 3$, while $\mathrm{HG}$ increases pro-inflammatory genes concomitantly with decreased levels of H3K9me3 and Suv39h1 at their promoters in vascular smooth muscle cells (25). However, the roles of Suv39h1 in diabetic nephropathy remain unclear. As a result, the study investigated whether HG-induced pro-fibrotic collagen IV and fibronectin is associated with reduced Suv39h1 levels and the effects of KMUP-1 on HG-decreased Suv39h1 levels. KMUP-1 $(10 \mu \mathrm{M})$ was demonstrated to attenuate HG-decreased Suv39h1 (Fig. 6A) and H3K9me3 (Fig. 6B) levels at $72 \mathrm{~h}$.

KMUP-1 attenuated collagen type IV and fibronectin expression in STZ-diabetic rats. To corroborate the in vitro findings, the effects of intraperitoneal KMUP-1 (5 mg/kg/day) treatment on STZ-diabetic rats were investigated at 8 weeks. Increased glomerular and tubular expression of collagen IV were both attenuated by KMUP-1 in diabetic rats (Fig. 7). Furthermore, increased peri-glomerular and tubulointerstitial expression of fibronectin was attenuated by KMUP-1 in diabetic rats (Fig. 8).

\section{Discussion}

KMUP-1 was demonstrated to attenuate HG-induced TGF- $\beta 1$ and TGF- $\beta 1$-induced Smad2/3 signaling in mesangial cells. In addition, KMUP-1 attenuated HG or TGF- $\beta 1$-induced collagen IV and fibronectin expression and HG-induced cell hypertrophy while attenuating HG-decreased Suv39h1 expression in mesangial cells. In addition, KMUP-1 attenuated collagen IV and fibronectin expression in STZ-diabetic rats. The observations provide mechanistic insights into the role of KMUP-1 in the attenuation of diabetic rat glomerulosclerosis.

The finding that KMUP-1, an eNOS-NO-sGC-cGMP enhancer (6), attenuated HG-induced TGF- $\beta 1$ and its Smad2/3 signaling corroborates the notion that $\mathrm{DN}$ is associated with a deficiency of NO (22). Notably, it was identified KMUP-1 attenuated TGF- $\beta 1$-induced $\mathrm{p}$-Smad $2 / 3$ expression only at 5-10 min. Similarly, NO has been identified to delay (however not abolish) TGF- $\beta 1$-induced $\mathrm{p}-\mathrm{Smad} 2 / 3$ expression from 15-60 min in endothelial cells (26). Previous studies indicated that HG induces TGF- $\beta 1$ by decreasing NO and cGMP (27).

In the present study, KMUP-1 attenuated HG- or TGF- $\beta 1$-induced collagen IV and fibronectin expression while attenuating cell hypertrophy. These observations corroborate with a previous study demonstrating that overexpression of cGMP-dependent protein kinase attenuates HG-induced TGF- $\beta 1$ and expression of collagen or fibronectin in mesangial cells (28). In addition, sGC enhancers decrease DN in eNOS-knockout mice in combination with angiotensin II type I receptor blockade (29). Thus, sGC enhancers may be renoprotective in DN (24) by attenuating TGF- $\beta 1$-induced effects. Similarly, a previous study identified that eNOS deficiency induces diabetic renal hypertrophy and glomerulosclerosis in mice (23). 
A

B

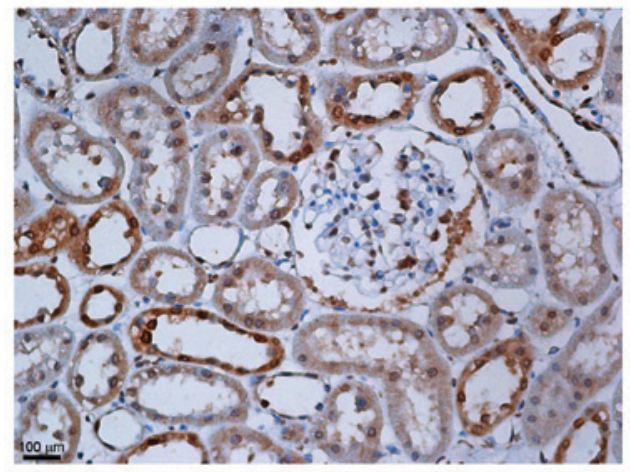

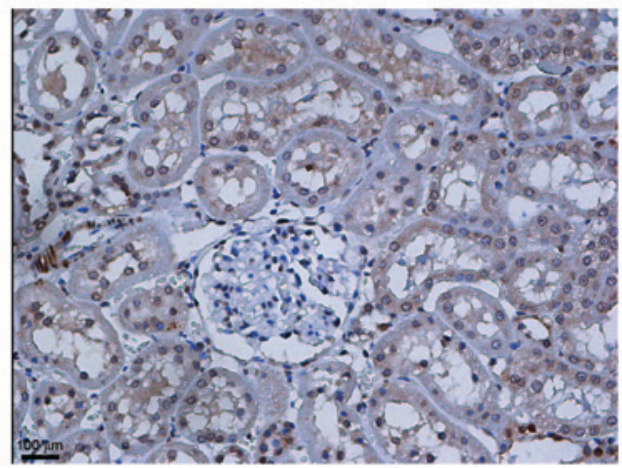

C

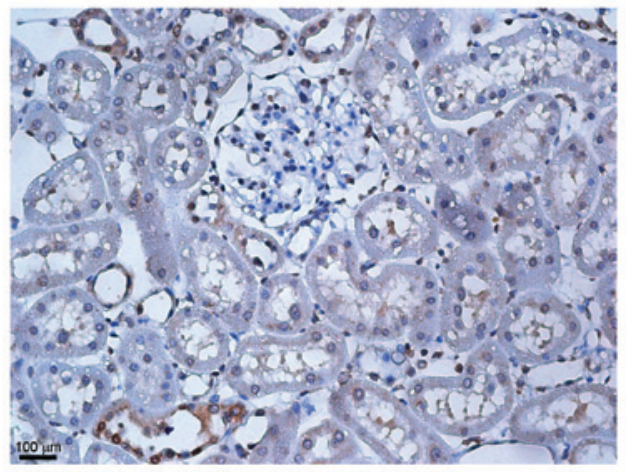

Figure 7. Effects of KMUP-1 on renal cortical collagen IV protein expression in STZ-diabetic rats. STZ-diabetic rats were intraperitoneally injected with KMUP-1 ( $5 \mathrm{mg} / \mathrm{kg} /$ day) daily for 8 weeks. Rats were perfused with normal saline and anesthetized on week 8 . Kidneys were removed and immersed in $4 \%$ paraformaldehyde. Kidney slices were embedded in the paraffin block and cut into $4 \mu \mathrm{m}$ sections for immunohistochemical (collagen IV) studies. The studies conducted experimentation on (A) a control rat, (B) a diabetic rat and (C) a diabetic + KMUP-1 rat. STZ, streptozotocin.

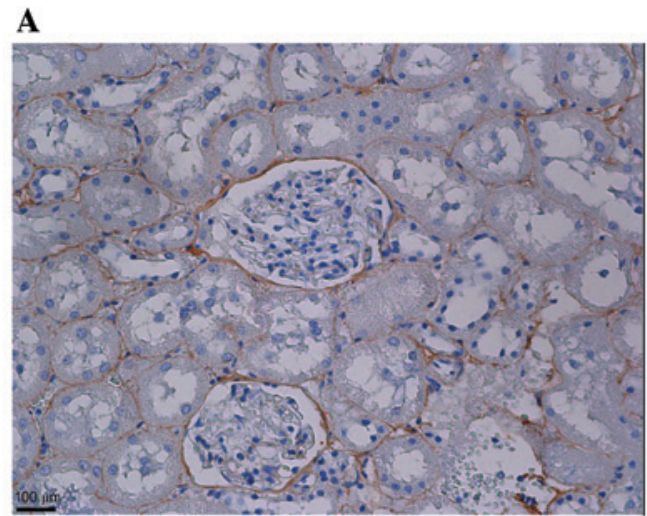

B

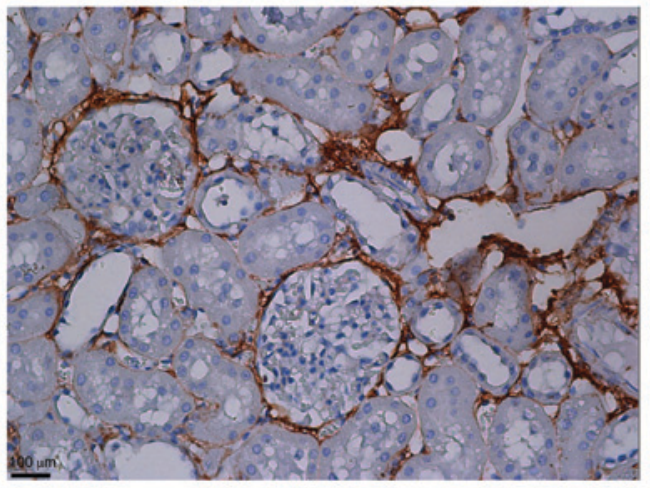

$\mathbf{C}$

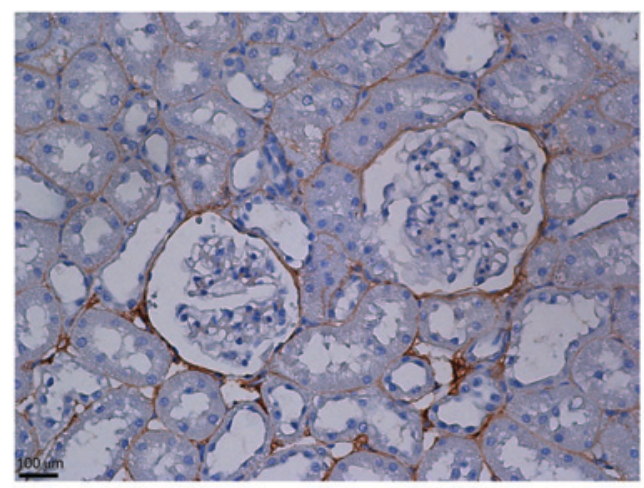

Figure 8. Effects of KMUP-1 on renal cortical fibronectin protein expression in STZ-diabetic rats. STZ-diabetic rats were intraperitoneally injected with KMUP-1 ( $5 \mathrm{mg} / \mathrm{kg} /$ day $)$ daily for 8 weeks. Rats were perfused with normal saline and anesthetized on week 8 . Kidneys were removed and immersed in $4 \%$ paraformaldehyde. Kidney slices were embedded in the paraffin block and cut into $4 \mu \mathrm{m}$ sections for immunohistochemical (fibronectin) studies on (A) a control rat, (B) a diabetic rat and (C) a diabetic + KMUP-1 rat. STZ, streptozotocin. 
The present study presented that KMUP-1 attenuated HG-decreased Suv39h1 and H3K9me3 expression. Similarly, additional studies indicated that Suv39h1 is decreased in diabetic mouse vascular smooth muscle cells (30), while occupancy of $\mathrm{H} 3 \mathrm{~K} 9 \mathrm{me} 3$ on some pro-fibrotic genes is decreased in diabetic mouse glomeruli (31). Thus, the decreased gene-silencing activity of Suv39h1 may be one of the pro-fibrotic mechanisms in DN. Notably, Suv39h1 protects from myocardial ischemia-reperfusion injury in diabetic rats (32).

The in vitro results were corroborated with the in vivo results that KMUP-1 attenuated increased expression of collagen IV and fibronectin in STZ-diabetic rats. This is in agreement with a previous study observing that KMUP-1 attenuates rat DN while increasing glomerular eNOS and decreasing matrix metalloproteinase-9 (MMP-9) expression (7). The attenuation of MMP-9 expression by KMUP-1 (7) may be an additional anti-fibrotic mechanism in that MMP-9 inhibitors attenuate HG-induced TGF- $\beta 1$ (33) and attenuate DN (34).

In conclusion, KMUP-1 attenuates HG- and TGF- $\beta 1$-induced pro-fibrotic proteins within mesangial cells. In addition, attenuation of TGF- $\beta 1$-induced Smad $2 / 3$ signaling and attenuation of HG-decreased Suv39h1 expression may be two of the anti-fibrotic mechanisms of KMUP-1. These observations provide novel mechanistic insight into the previously observed attenuation of diabetic rat glomerulosclerosis by KMUP-1.

\section{Acknowledgements}

The authors would like to thank the staff of the Department of Pharmacology from the Kaohsiung Medical University (Kaohsiung, Taiwan) for the assistance with the pharmaceutical properties of KMUP-1. We also thank Dr Jean-Louis Virelizier (Unité d'Immunologie Virale, Institut Pasteur, Paris, France) and Dr Joan Massagué (Memorial Sloan Kettering Cancer Center, New York, NY, USA) for the plasmids.

\section{References}

1. Perkovic V, Agarwal R, Fioretto P, Hemmelgarn BR, Levin A, Thomas MC, Wanner C, Kasiske BL, Wheeler DC and Groop PH Conference Participants: Management of patients with diabetes and CKD: Conclusions from a 'Kidney disease: Improving global outcomes' (KDIGO) controversies conference. Kidney Int 90: 1175-1183, 2016.

2. Kolset SO, Reinholt FP and Jenssen T: Diabetic nephropathy and extracellular matrix. J Histochem Cytochem 60: 976-986, 2012.

3. Kanwar YS, Sun L, Xie P, Liu FY and Chen S: A glimpse of various pathogenetic mechanisms of diabetic nephropathy. Annu Rev Pathol 6: 395-423, 2011.

4. Lan HY: Transforming growth factor- $\beta /$ Smad signalling in diabetic nephropathy. Clin Exp Pharmacol Physiol 39: 731-738, 2012.

5. Huang JS, Chuang LY, Guh JY, Chen CJ, Yang YL, Chiang TA, Hung MY and Liao TN: Effect of nitric oxide-cGMP-dependent protein kinase activation on advanced glycation end-product-induced proliferation in renal fibroblasts. J Am Soc Nephrol 16: 2318-2329, 2005.

6. Wu BN, Chen CW, Liou SF, Yeh JL, Chung $\mathrm{HH}$ and Chen IJ: Inhibition of proinflammatory tumor necrosis factor-\{alpha\}-induced inducible nitric-oxide synthase by xanthine-based 7-[2-[4-(2-chlorobenzene)piperazinyl] ethyl]-1,3-dimethylxanthine (KMUP-1) and 7-[2-[4-(4-nitrobenzene)piperazinyl]ethyl]-1, 3-dimethylxanthine (KMUP-3) in rat trachea: The involvement of soluble guanylate cyclase and protein kinase G. Mol Pharmacol 70: 977-985, 2006.
7. Hong TY, Guh JY, Wu BN, Chai CY, Huang HT and Chen IJ: KMUP-1 protects kidney from Streptozotocin-induced proinflammation in early diabetic nephropathy by restoring eNOS/ PPARgamma and inhibiting MMP-9. European Journal of Inflammation 12: 89-100, 2014

8. Wu BN, Lin RJ, Lin CY, Shen KP, Chiang LC and Chen IJ: A xanthine-based KMUP-1 with cyclic GMP enhancing and $\mathrm{K}(+)$ channels opening activities in rat aortic smooth muscle. Br J Pharmacol 134: 265-274, 2001

9. Lin RJ, Wu BN, Lo YC, Shen KP, Lin YT, Huang CH and Chen IJ: KMUP-1 relaxes rabbit corpus cavernosum smooth muscle in vitro and in vivo: Involvement of cyclic GMP and $\mathrm{K}(+)$ channels. Br J Pharmacol 135: 1159-1166, 2002.

10. Wu BN, Lin RJ, Lo YC, Shen KP, Wang CC, Lin YT and Chen IJ: KMUP-1, a xanthine derivative, induces relaxation of guinea-pig isolated trachea: The role of the epithelium, cyclic nucleotides and $\mathrm{K}^{+}$channels. Br J Pharmacol 142: 1105-1114, 2004.

11. Michelson S, Alcami J, Kim SJ, Danielpour D, Bachelerie F, Picard L, Bessia C, Paya C and Virelizier JL: Human cytomegalovirus infection induces transcription and secretion of transforming growth factor beta 1. J Virol 68: 5730-5737, 1994.

12. Wrana JL, Attisano L, Cárcamo J, Zentella A, Doody J, Laiho M, Wang XF and Massagué J: TGF beta signals through a heteromeric protein kinase receptor complex. Cell 71: 1003-1014, 1992.

13. Huang JS, Guh JY, Hung WC, Yang ML, Lai YH, Chen HC and Chuang LY: Role of the Janus kinase (JAK)/signal transducters and activators of transcription (STAT) cascade in advanced glycation end-product-induced cellular mitogenesis in NRK-49F cells. Biochem J 342: 231-238, 1999.

14. Huang JS, Chuang LY, Guh JY, Huang YJ and Hsu MS: Antioxidants attenuate high glucose-induced hypertrophic growth in renal tubular epithelial cells. Am J Physiol Renal Physiol 293: F1072-F1082, 2007.

15. Shin SJ, Lai FJ, Wen JD, Hsiao PJ, Hsieh MC, Tzeng TF, Chen HC, Guh JY and Tsai JH: Neuronal and endothelial nitric oxide synthase expression in outer medulla of streptozotocin-induced diabetic rat kidney. Diabetologia 43: 649-659, 2000.

16. Dai ZK, Lin TC, Liou JC, Cheng KI, Chen JY, Chu LW, Chen IJ and Wu BN: Xanthine derivative KMUP-1 reduces inflammation and hyperalgesia in a bilateral chronic constriction injury model by suppressing MAPK and NFאB activation. Mol Pharm 11: 1621-1631, 2014.

17. Tsai CW (ed): A Guidebook for the Care and Use of Laboratory Animals. 3rd edition. Taiwan Council of Agriculture, Taipei, Taiwan, 2010 (In Chinese).

18. Yano N, Suzuki D, Endoh M, Cao TN, Dahdah JR, Tseng A, Stabila JP, McGonnigal BG, Padbury JF and Tseng YT: High ambient glucose induces angiotensin-independent AT-1 receptor activation, leading to increases in proliferation and extracellular matrix accumulation in MES-13 mesangial cells. Biochem J 423: 129-143, 2009.

19. Jiang T, Che Q, Lin Y, Li H and Zhang N: Aldose reductase regulates TGF-beta1-induced production of fibronectin and type IV collagen in cultured rat mesangial cells. Nephrology (Carlton) 11: 105-112, 2006.

20. Yeh JL, Hsu JH, Wu PJ, Liou SF, Liu CP, Chen IJ, Wu BN, Dai ZK and Wu JR: KMUP-1 attenuates isoprenaline-induced cardiac hypertrophy in rats through NO/cGMP/PKG and ERK1/2/calcineurin A pathways. Br J Pharmacol 159: 1151-1160, 2010.

21. Goruppi S, Bonventre JV and Kyriakis JM: Signaling pathways and late-onset gene induction associated with renal mesangial cell hypertrophy. EMBO J 21: 5427-5436, 2002.

22. Tessari P: Nitric oxide in the normal kidney and in patients with diabetic nephropathy. J Nephrol 28: 257-268, 2015.

23. Nakagawa T, Sato W, Glushakova O, Heinig M, Clarke T, Campbell-Thompson M, Yuzawa Y, Atkinson MA, Johnson RJ and Croker B: Diabetic endothelial nitric oxide synthase knockout mice develop advanced diabetic nephropathy. J Am Soc Nephrol 18: 539-550, 2007.

24. Stasch JP, Schlossmann J and Hocher B: Renal effects of soluble guanylate cyclase stimulators and activators: A review of the preclinical evidence. Curr Opin Pharmacol 21: 95-104, 2015.

25. Reddy MA, Zhang E and Natarajan R: Epigenetic mechanisms in diabetic complications and metabolic memory. Diabetologia 58: 443-455, 2015.

26. Saura M, Zaragoza C, Herranz B, Griera M, Diez-Marqués L, Rodriguez-Puyol D and Rodriguez-Puyol M: Nitric oxide regulates transforming growth factor-beta signaling in endothelial cells. Circ Res 97: 1115-1123, 2005. 
27. Wang S, Shiva S, Poczatek MH, Darley-Usmar V and Murphy-Ullrich JE: Nitric oxide and cGMP-dependent protein kinase regulation of glucose-mediated thrombospondin 1-dependent transforming growth factor-beta activation in mesangial cells. J Biol Chem 277: 9880-9888, 2002.

28. Wang S, Wu X, Lincoln TM and Murphy-Ullrich JE: Expression of constitutively active cGMP-dependent protein kinase prevents glucose stimulation of thrombospondin 1 expression and TGF-beta activity. Diabetes 52: 2144-2150, 2003.

29. Ott IM, Alter ML, von Websky K, Kretschmer A, Tsuprykov O, Sharkovska Y, Krause-Relle K, Raila J, Henze A, Stasch JP and Hocher B: Effects of stimulation of soluble guanylate cyclase on diabetic nephropathy in diabetic eNOS knockout mice on top of angiotensin II receptor blockade. PLoS One 7: e42623, 2012.

30. Villeneuve LM, Reddy MA, Lanting LL, Wang M, Meng L and Natarajan R: Epigenetic histone H3 lysine 9 methylation in metabolic memory and inflammatory phenotype of vascular smooth muscle cells in diabetes. Proc Natl Acad Sci USA 105 9047-9052, 2008.
31. Reddy MA, Sumanth P, Lanting L, Yuan H, Wang M, Mar D, Alpers CE, Bomsztyk K and Natarajan R: Losartan reverses permissive epigenetic changes in renal glomeruli of diabetic $\mathrm{db} / \mathrm{db}$ mice. Kidney Int 85: 362-373, 2014.

32. Yang B, Yang J, Bai J, Pu P, Liu J, Wang F and Ruan B: Suv39h1 protects from myocardial ischemia-reperfusion injury in diabetic rats. Cell Physiol Biochem 33: 1176-1185, 2014.

33. Wu L and Derynck R: Essential role of TGF-beta signaling in glucose-induced cell hypertrophy. Dev Cell 17: 35-48, 2009.

34. Williams JM,Zhang J, North P, Lacy S, Yakes M, Dahly-Vernon A and Roman RJ: Evaluation of metalloprotease inhibitors on hypertension and diabetic nephropathy. Am J Physiol Renal Physiol 300: F983-F998, 2011. 